\title{
Predictors of Erectile Dysfunction in Men with Type 2 Diabetes Mellitus Referred to a Tertiary Healthcare Centre
}

\author{
Theophilus Ugwu,, ${ }^{1}$ Ignatius Ezeani, ${ }^{2}$ Samuel Onung, \\ Babatope Kolawole, ${ }^{4}$ and Rosemary Ikem ${ }^{4}$ \\ ${ }^{1}$ Department of Internal Medicine, College of Medicine, Enugu State University of Science and Technology, PMB 01660, Enugu, Nigeria \\ ${ }^{2}$ Department of Internal Medicine, Federal Medical Centre, Umuahia, Nigeria \\ ${ }^{3}$ Department of Internal Medicine, University of Uyo Teaching Hospital, Uyo, Nigeria \\ ${ }^{4}$ Department of Internal Medicine, Obafemi Awolowo University Teaching Hospital, Ile-Ife, Nigeria
}

Correspondence should be addressed to Theophilus Ugwu; ofornet@yahoo.com

Received 26 August 2015; Revised 30 January 2016; Accepted 18 February 2016

Academic Editor: Massimiliano Ruscica

Copyright (C) 2016 Theophilus Ugwu et al. This is an open access article distributed under the Creative Commons Attribution License, which permits unrestricted use, distribution, and reproduction in any medium, provided the original work is properly cited.

Background. The frequency of erectile dysfunction (ED) complicating diabetes mellitus (DM) is reportedly high. However, its risk factors have not been well studied. Methods. This was a cross-sectional study of 160 male type 2 DM adults, aged 30-70 years, attending a tertiary healthcare clinic. Demographic and relevant clinical information was documented. Erectile function was assessed using an abridged version of the International Index of Erectile Function (IIEF-5). All subjects were evaluated for central obesity, glycemic control, peripheral arterial disease (PAD), autonomic neuropathy, dyslipidemia, and testosterone deficiency. Results. 152 (95\%) patients with a mean age of $60.3 \pm 8.8$ years completed the study. $71.1 \%$ had varying degrees of $\mathrm{ED}$, while $58.3 \%$ suffered from a moderate-to-severe form. Independent predictors of ED [presented as adjusted odds ratio ( $95 \%$ confidence interval)] were longer duration of DM, 1.14 (1.02-1.28), PAD, 3.87 (1.28-11.67), autonomic neuropathy, 3.51 (1.82-6.79), poor glycemic control, 7.12 (2.49-20.37), and testosterone deficiency, 6.63 (2.61-16.83). Conclusion. The prevalence of ED and its severe forms was high in this patient population. Poor glycemic control and testosterone deficiency were the strongest risk factors for ED, making it possibly a preventable condition.

\section{Introduction}

Diabetes mellitus (DM) is a chronic metabolic disorder associated with significant morbidity and mortality. Various forms of sexual dysfunction occur in men with DM, including disorders of libido, ejaculatory problems, and erectile dysfunction (ED). Erectile dysfunction is defined as the persistent inability to achieve or maintain penile erection sufficient for satisfactory sexual performance [1]. With a reported prevalence of 35 to $85 \%$ [2,3], ED is one of the most common complications of DM. In the Massachusetts Male Aging Study [4], the age-adjusted probability of complete impotence was three times greater $(28 \%)$ in patients with treated diabetes than in controls $(9.6 \%)$. In addition to its higher frequency, ED also occurs at an earlier age in the diabetic population as compared with the general population $[3,4]$. Erectile dysfunction is associated with grave psychosocial and clinical consequences including depression and poor quality of life [5]. In fact, there is a vicious cycle between ED, depression, and glycemic control $[6,7]$. Poor glycemic control is associated with both microvascular and macrovascular complications in both type 1 diabetes and type 2 diabetes, thereby making ED a major issue requiring serious attention in the diabetic population. Besides, there is evidence that ED is a risk factor for cardiovascular diseases and an early marker for coronary artery disease which is the leading cause of mortality in patients with DM [8]. Despite the aforementioned clinical importance of ED in diabetic men, studies have shown that most clinicians do not enquire about sexual dysfunction during consultations and the prevalence 
of self-reported ED is very low [9]. Thus ED has remained one of the most underdiagnosed yet common complications of DM. This study was aimed at determining the prevalence and risk factors for ED among men with type $2 \mathrm{DM}$ in a Nigerian tertiary healthcare centre.

\section{Methods}

This was a cross-sectional survey involving 160 males aged 30-70 years who had been diagnosed with type 2 DM according to the 1999 World Health Organization's criteria. Subjects were consecutively recruited from the outpatient diabetes clinic of the Obafemi Awolowo University Teaching Hospital, Ile-Ife, situated in the Southwest geopolitical zone of Nigeria, after obtaining a written informed consent. The hospital's Research and Ethics Committee approved the research protocol. Subjects with conditions that could significantly affect penile erection regardless of diabetes were excluded. These include genital anatomic deformities, spinal cord injuries, and known or suspected chronic debilitating illnesses such as chronic heart failure, chronic liver disease, chronic renal failure, tuberculosis, chronic obstructive pulmonary diseases, and malignancy. Subjects who received phosphodiesterase inhibitor therapy in the past one month were also excluded.

A structured questionnaire was used to document relevant demographic and clinical information such as age, cigarette smoking history, and duration of DM. Central obesity was defined as waist circumference (WC) $\geq 94$ centimeters [10]. It was measured at a point midway between the inferior border of the costal margin and the iliac crest in midaxillary line. Peripheral arterial disease (PAD) was evaluated using the ankle brachial index (ABI) which was calculated as the ratio of ankle systolic blood pressure (BP) to that of the arm after taking measurements according to a standardized method [11]. A value of 0.9 or less in at least one leg confirmed a diagnosis of PAD. The ABI was categorized as normal (0.91-1.3), mild obstruction (0.7$0.9)$, moderate obstruction (0.4-0.69), and severe obstruction $(<0.4)$, while subjects with $\mathrm{ABI}>1.3$ were classified as "poorly compressible" and excluded from the analysis. Diagnosis of autonomic neuropathy was made clinically using the modified Ewing criteria after cardiovascular autonomic function tests involving three heart rate (HR) tests with simultaneous electrocardiographic recording and two BP tests [12]. Subjects were classified according to the degree of autonomic dysfunction as follows: normal (all 5 tests normal or 1 borderline), early neuropathy ( $1 \mathrm{HR}$ test abnormal or 2 borderline), definite neuropathy ( 2 or more HR tests abnormal), and severe neuropathy ( 2 or more HR tests plus at least $1 \mathrm{BP}$ test abnormal or both BP tests borderline).

2.1. Assessment of Erectile Function. All subjects completed the abridged version of the International Index of Erectile Function (IIEF-5) [13]. It is a 5-stem questionnaire that more concisely addresses the erectile domain of male sexuality and has been used across different cultures including Nigeria [14, 15]. The scores range from 0 to 25 . Erectile function status of the subjects was classified as follows: normal erectile function (score > 21), mild ED (score 17-21), mild-to-moderate ED (score 12-16), moderate ED (score 8-11), and severe ED (score $<8)$.

2.2. Laboratory Evaluation. After an overnight fast, $10 \mathrm{~mL}$ of venous blood was obtained from each patient via a sterile venipuncture between 8.00 and 10.00 a.m. and shared between a plain bottle and one containing ethylenediaminetetraacetic acid. The anticoagulated sample was used to analyze glycated hemoglobin (HbAlc) (boronate affinity chromatography, in2it, Bio-Rad Laboratories) and lipids (spectroscopy technique, Lipid pro $^{\mathrm{TM}}$, Infopia Co., Ltd.). Subjects with HbAlc $<7 \%$ were regarded as having good glycemic control. Dyslipidemia was diagnosed if any of the following was present: total cholesterol $>4.5 \mathrm{mmol} / \mathrm{L}$, low density lipoprotein $>2.6 \mathrm{mmol} / \mathrm{L}$, triglycerides $>1.7 \mathrm{mmol} / \mathrm{L}$, high density lipoprotein $<1.1 \mathrm{mmol} / \mathrm{L}$, or non-high density lipoprotein $>3.4 \mathrm{mmol} / \mathrm{L}$. The clotted sample was centrifuged at 3000 revolutions per minute for five minutes to extract the serum. This was stored frozen and used for measurement of total testosterone by enzyme-linked immunosorbent assay technique (Fortress Diagnostics, United Kingdom). Total testosterone concentrations $<8 \mathrm{nmol} / \mathrm{L}$, between 8 and $12 \mathrm{nmol} / \mathrm{L}$, and $>12 \mathrm{nmol} / \mathrm{L}$ were defined as low, borderline, and normal, respectively, according to expert recommendations [16].

Data were entered into a personal computer and analyzed using the Statistical Package for Social Sciences version 17.0. The data were summarized using descriptive statistics such as tables and graphs as appropriate. Discrete variables were represented by frequencies and percentages, while means and standard deviations were used for continuous variables. The Chi-Square test was employed to analyze discrete variables for association with ED, while continuous variables were analyzed using Student's $t$-test. To test for independent determinants of ED, all the variables that showed significant association with ED at the univariate level of analysis were subjected to a stepwise (backward) binary logistic regression to compute their odds ratio and confidence intervals. Statistical significance was established at $P<0.05$.

\section{Results}

152 out of 160 subjects completed the study, giving a response rate of $95 \%$. One person had an ankle brachial index $>1.3$ and was excluded, while 7 subjects did not complete the study.

3.1. Sociodemographic and Clinical Characteristics of the Study Population. Table 1 shows the baseline characteristics of the subjects. The mean age was $60.3 \pm 8.8$ years and mean duration of DM was $6.0 \pm 4.2$ years. Central obesity was present in $50.7 \%$, while $63.8 \%$ of patients were hypertensive. The majority $(84.4 \%)$ of the participants were on oral hypoglycemic agents and over half of them (56.6\%) had poor glycemic control ( $\mathrm{HbAlc} \geq 7 \%$ ). Early, definite, and severe autonomic neuropathy was observed in $27.6 \%, 13.2 \%$, and $10.5 \%$, respectively, while $37.5 \%$ had low testosterone concentration, $<8 \mathrm{nmol} / \mathrm{L}$. 
TABLE 1: Baseline characteristics of the participants.

\begin{tabular}{|c|c|c|c|}
\hline Variable & Mean $( \pm$ SD $)$ & Frequency & Percentage \\
\hline Age (years) & $60.3( \pm 8.8)$ & & \\
\hline $30-45$ & & 11 & 7.2 \\
\hline $46-64$ & & 79 & 52.0 \\
\hline $65-70$ & & 62 & 40.8 \\
\hline Cigarette smoking (pack-years) & $1.3( \pm 3.7)$ & & \\
\hline Never smoked & & 111 & 73.0 \\
\hline$\leq 5$ & & 33 & 21.7 \\
\hline $6-10$ & & 4 & 2.6 \\
\hline$>10$ & & 4 & 2.6 \\
\hline Waist circumference $(\mathrm{cm})$ & $94.1( \pm 11.2)$ & & \\
\hline$<94$ & & 75 & 49.3 \\
\hline$\geq 94$ & & 77 & 50.7 \\
\hline Duration of diabetes (years) & $6.0( \pm 4.2)$ & & \\
\hline $1-5$ & & 82 & 53.9 \\
\hline $6-10$ & & 42 & 27.6 \\
\hline $11-15$ & & 28 & 18.4 \\
\hline \multicolumn{4}{|l|}{ Treatment modality } \\
\hline OHA alone & & 128 & 84.2 \\
\hline Insulin alone & & 3 & 1.9 \\
\hline OHA + Insulin & & 21 & 13.8 \\
\hline \multicolumn{4}{|l|}{ Hypertension } \\
\hline Present & & 97 & 63.8 \\
\hline Absent & & 55 & 36.2 \\
\hline \multicolumn{4}{|l|}{ Ankle brachial index } \\
\hline Normal (0.91-1.3) & & 98 & 64.5 \\
\hline Mild obstruction (0.7-0.9) & & 35 & 23.0 \\
\hline Moderate obstruction (0.4-0.69) & & 19 & 12.5 \\
\hline Severe obstruction $(<0.4)$ & & 0 & 0 \\
\hline \multicolumn{4}{|l|}{ Autonomic function assessment } \\
\hline Normal & & 74 & 48.7 \\
\hline Early neuropathy & & 42 & 27.6 \\
\hline Definite neuropathy & & 20 & 13.2 \\
\hline Severe neuropathy & & 16 & 10.5 \\
\hline Glycated hemoglobin (\%) & $7.7( \pm 1.7)$ & & \\
\hline Good (HbAlc < 7) & & 66 & 43.4 \\
\hline Poor (HbAlc $\geq 7)$ & & 86 & 56.6 \\
\hline Serum testosterone $(\mathrm{nmol} / \mathrm{L})$ & $13.2( \pm 7.9)$ & & \\
\hline Normal (>12) & & 60 & 39.5 \\
\hline Borderline (8-12) & & 35 & 23.0 \\
\hline Low $(<8)$ & & 57 & 37.5 \\
\hline \multicolumn{4}{|l|}{ Dyslipidemia } \\
\hline Present & & 51 & 33.6 \\
\hline Absent & & 101 & 66.4 \\
\hline
\end{tabular}

Data are in numbers (percentages) or means (standard deviations). OHA = oral hypoglycemic agents.

3.2. Prevalence of Erectile Dysfunction in the Study Population. Of the 152 men who completed the study, 108 (71.1\%) had varying degrees of erectile dysfunction. The erectile function scores of the subjects are presented in Table 2.
3.3. Associations of Variables with Erectile Dysfunction. Table 3 shows a comparative analysis of the sociodemographic, clinical, and laboratory variables between the participants who had ED and controls. Subjects who had ED 
TABLE 2: Erectile function scores of the study population.

\begin{tabular}{lcc}
\hline Erectile function status & Frequency & Percentage \\
\hline Normal erectile function (IIEF-5 score $>$ 21) & 44 & 28.9 \\
Mild ED (IIEF-5 score 17-21) & 29 & 19.1 \\
Mild-to-moderate ED (IIEF-5 score 12-16) & 16 & 10.5 \\
Moderate ED (IIEF-5 score 8-11) & 12 & 7.9 \\
Severe ED (IIEF-5 score $<$ 8) & 51 & 33.6 \\
Total & $\mathbf{1 5 2}$ & $\mathbf{1 0 0 . 0}$ \\
\hline
\end{tabular}

$\mathrm{ED}=$ erectile dysfunction; IIEF = International Index of Erectile Function.

TABLE 3: Associations between variables and erectile dysfunction.

\begin{tabular}{|c|c|c|c|}
\hline Variable & $\begin{array}{c}\text { ED absent } \\
(n=44)\end{array}$ & $\begin{array}{c}\text { ED present } \\
(n=108)\end{array}$ & $P$ value \\
\hline Age (years) & $56.6 \pm 10.2$ & $61.8 \pm 7.7$ & $0.001^{*}$ \\
\hline Waist circumference $(\mathrm{cm})$ & $93.3 \pm 10.1$ & $94.4 \pm 11.4$ & 0.59 \\
\hline Cigarette smoking, $n(\%)$ & $10(22.7)$ & $34(31.5)$ & 0.28 \\
\hline Duration of diabetes (years) & $4.4 \pm 3.5$ & $6.7 \pm 4.4$ & $0.003^{*}$ \\
\hline Hypertension, $n(\%)$ & $25(56.8)$ & $72(66.7)$ & 0.25 \\
\hline Peripheral arterial disease, $n(\%)$ & $6(13.6)$ & $48(44.4)$ & $<0.001^{*}$ \\
\hline Autonomic neuropathy, $n(\%)$ & $12(27.3)$ & $66(61.1)$ & $<0.001^{*}$ \\
\hline $\operatorname{HbAlc}(\%)$ & $6.8 \pm 0.8$ & $8.0 \pm 1.9$ & $<0.001^{*}$ \\
\hline Serum testosterone $(\mathrm{nmol} / \mathrm{L})$ & $18.4 \pm 9.1$ & $11.0 \pm 6.3$ & $<0.001^{*}$ \\
\hline Dyslipidemia, $n(\%)$ & $14(23.1)$ & $37(31.9)$ & 0.33 \\
\hline Total cholesterol (mmol/L) & $4.2 \pm 0.9$ & $4.4 \pm 1.0$ & 0.47 \\
\hline Triglycerides (mmol/L) & $1.3 \pm 0.5$ & $1.4 \pm 0.5$ & 0.32 \\
\hline LDL cholesterol (mmol/L) & $1.9 \pm 0.5$ & $2.1 \pm 0.7$ & 0.19 \\
\hline HDL cholesterol (mmol/L) & $1.3 \pm 1.4$ & $1.2 \pm 0.2$ & 0.22 \\
\hline Non-HDL cholesterol $(\mathrm{mmol} / \mathrm{L})$ & $3.1 \pm 1.1$ & $3.3 \pm 0.9$ & 0.14 \\
\hline
\end{tabular}

Data are in means (standard deviations) or numbers (percentages). $*=$ significant with $P$ value $<0.05 . \mathrm{ED}=$ erectile dysfunction; HbAlc $=$ glycated hemoglobin; LDL = low density lipoprotein; HDL = high density lipoprotein. Non-HDL cholesterol = TC - HDL cholesterol.

were significantly older than control subjects (mean age of $61.8 \pm 7.7$ years versus $56.6 \pm 10.2$ years; $P$ 0.001). Waist cir-

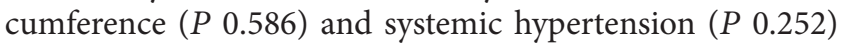
were not significantly associated with ED. Subjects with ED had a longer duration of DM (mean: $6.7 \pm 4.4$ years) than those without $\mathrm{ED}$ whose mean DM duration was $4.4 \pm 3.5$ years $(P=$ 0.003). Peripheral arterial disease, autonomic neuropathy, poor glycemic control, and testosterone deficiency were all significantly associated with $\mathrm{ED}(P<0.001$, resp.). The mean HbAlc of the subjects who had ED and the controls was, respectively, $8.0 \pm 1.9 \%$ and $6.8 \pm 0.8 \%$.

3.4. Independent Predictors of Erectile Dysfunction. Following a stepwise (backward) logistic regression of the studied variables, duration of DM ( $P$ 0.024), peripheral arterial disease $(P$ 0.016), poor glycemic control $(P<0.001)$, and testosterone deficiency $(P<0.001)$ were found to be significant independent predictors of ED in the study population (Table 4). Autonomic neuropathy became significant $(P<0.001)$ only when duration of diabetes was removed from the regression model. This was explained by a significant collinearity between duration of DM and autonomic neuropathy with Spearman's correlation coefficient of 0.69 (P 0.01).

\section{Discussion}

Nearly three-quarters of the participants in this study had varying degrees of ED. This has confirmed that ED is indeed a common complication of DM as had been severally reported $[3,14,17]$. Few authors have however reported a lower prevalence of ED in men with diabetes. In a study of 96 men with diabetes at Lagos, Nigeria, Ogbera and Adedokun [15] observed only $34 \%$ prevalence of ED. Similarly, a multicentre study involving 9,756 diabetic men in Italy documented a lower prevalence of $37 \%$ [18]. These divergent prevalence rates may be accounted for by differences in the populations studied including but not limited to population sizes, demographic characteristics, duration and severity of diabetes, and presence of other confounding comorbidities. Nevertheless, most authors agree that ED is not only a common complication of DM, but it is also frequently underdiagnosed. This high frequency of ED in men with diabetes is worrisome owing to the profound negative impact of $\mathrm{ED}$ on the quality 
TABLE 4: Independent predictors of ED in the study population.

\begin{tabular}{lcccc}
\hline Variables & OR for ED & $95 \%$ CI & $P$ value \\
\hline Age $>60$ years & 1.17 & $0.81-1.14$ & 0.063 \\
Duration of DM (5-year increments) & 1.14 & $1.02-1.28$ & $0.024^{*}$ \\
Peripheral arterial disease (present) & 3.87 & $1.28-11.67$ & $0.016^{*}$ \\
HbAlc $\geq 7 \%$ & 7.12 & $2.49-20.37$ & $<0.001^{*}$ \\
Testosterone $<8$ nmol/L & 6.63 & $2.61-16.83$ & $<0.001^{*}$ \\
Autonomic neuropathy (present) & 3.51 & $1.82-6.79$ & $<0.001^{*}$ \\
\hline
\end{tabular}

$\mathrm{DM}=$ diabetes mellitus; $\mathrm{ED}=$ erectile dysfunction; $\mathrm{HbAlc}=$ glycated hemoglobin .

* = significant with $P$ value $<0.05$.

of life of diabetics which in turn adversely affects diabetes control [6]. Poor glycemic control is associated with nearly all microvascular complications in type $2 \mathrm{DM}$, thereby making diabetes-related $\mathrm{ED}$ a major issue requiring serious attention.

Subjects who had ED were significantly older than controls on univariate analysis. Increasing age has consistently been shown to be a significant risk factor for ED both in the general population and in diabetic cohorts $[4,6]$. Aging is associated with a decline in several organ functions including cognitive, cardiac, hepatic, and renal functions and erectile function may not be an exception. Several of the well known risk factors for ED such as hypertension, hypogonadism, and atherosclerosis are also commoner with increasing age, and diabetes on its own increases the risk of developing many of these risk factors. On regression analysis, however, after controlling for these other risk factors, older age failed to be an independent predictor of ED (adjusted OR: 1.17; P 0.063). This suggests that older age may be acting indirectly through other risk factors for the development of ED in the diabetic subjects and this underscores the importance of controlling these other risk factors since aging is not modifiable.

Although cigarette smoking is a well recognized risk factor for ED in diabetics possibly through the acceleration of atherosclerosis which is the main pathogenic pathway for vasculogenic $\mathrm{ED}$ [17], this was not the case in our study. The reason for this finding is unclear. However, this might be related to the relatively small number of subjects who had ever smoked cigarette actively $(26.9 \%)$ in our study population. The use of questionnaires to assess smoking may have a social desirability issue that may diminish the association between smoking and ED. Moreover, though the proportion of current smokers was not assessed in this study, it is likely that a significant number of those who smoked might have quit the habit owing to continual campaign against smoking as part of lifestyle modification education programs in our diabetes clinic, coupled with the increasing level of poverty in Nigeria. A large prospective populationbased study in the United States had demonstrated that former smokers were not at increased risk of ED compared with nonsmokers, suggesting that the impact of smoking on erectile function wears off with time following cessation of smoking [4]. Whether this influenced the finding in our study remains to be elucidated.

A longer duration of DM was found to be an independent risk factor for ED (OR: 1.14, 95\% CI $=1.02-1.28$, and $P=$ $0.024)$. We observed that each 5 -year increment in the duration of DM conferred a $14 \%$ increase in the risk of having ED. This finding had been demonstrated in many other studies $[2,3,14,17,18]$. It is commonly known that many of the microvascular and macrovascular complications of DM increase with a longer duration of DM. It is therefore not surprising that the prevalence of diabetes-related ED which is mostly neurogenic and vasculogenic in etiology increases with a longer duration of DM. Other risk factors for ED such as poor glycemic control and testosterone deficiency have also been shown to be worse with increasing duration of DM $[19,20]$.

Hypertension is a well established risk factor for ED in the general population $[1,4]$. Similar findings have also been reported in the diabetic population $[17,18]$. This is not an unexpected finding since hypertension is closely related to the development and progression of atherosclerosis. In contrast, however, our study failed to show a significant association between hypertension and ED. Other investigators had also previously reported similar findings [14]. It has been suggested that the association observed in other studies may be due to antihypertensive medications rather than hypertension per se. Several antihypertensive medications have been linked to ED in the general population. The major culprits are thiazide diuretics, beta-blockers, and centrally acting drugs such as alpha-methyldopa. The probable impact of these medications on the finding in this study remains obscure.

This study demonstrated that the presence of PAD in persons with type 2 diabetes increases the risk of ED nearly fourfold. Peripheral arterial disease is a term used to describe occlusive and aneurysmal disease of the aorta and its branches excluding the coronary arteries [21]. It is a well recognized complication of DM in which it is usually more extensive and severe [22]. Diabetes accelerates atherogenesis leading to microvascular and macrovascular complications. The commonest clinical presentation of PAD is lower limb claudication [21]. However, this is a poor indicator of the presence of PAD as it may not develop until decades into the onset of the disease and may never even develop at all. Erectile dysfunction secondary to PAD often precedes the development of the classical symptoms of PAD by several years owing to the smaller diameter of penile arteries compared to the femoral and popliteal arteries. Atherosclerosis of the penile arteries has been shown to be a risk marker of generalized atherosclerosis and ED is now known to be an early sign of cardiovascular diseases including 
coronary artery disease $[8,23]$. Virtually all the participants who had moderate arterial obstruction and majority of those who had mild obstruction in this study had ED. Conversely, $44.4 \%$ of all the subjects who had ED suffered from PAD compared to $13.6 \%$ of those who did not have ED giving a ratio of more than $3: 1$. This lends credence to the close relationship between PAD and ED in diabetics.

Presence of autonomic neuropathy was associated with a threefold increase in the risk of ED on multivariate analysis. This finding is consistent with earlier reports which had established a close relationship between autonomic neuropathy and occurrence of ED in diabetics [24, 25]. Penile tissues are innervated by autonomic nerves which mediate both penile erection and semen ejaculation. Diabetes is one of the commonest causes of autonomic dysfunction which may even precede the diagnosis of type $2 \mathrm{DM}$. The pathogenesis of diabetic neuropathy is likely to be the same as the other diabetes complications, namely, neuronal dysmetabolism, leading to the formation of sorbitol and advanced glycosylation end products, oxidative stress, and microangiopathy of the vasa nervorum.

Of all the variables that were evaluated in this study, poor glycemic control was the most efficient independent predictor of ED (OR: 7.12, 95\% CI $=2.49-20.37$, and $P<0.001$ ). Our study revealed that patients with poor diabetes control (HbAlc $\geq 7 \%$ ) were at least seven times more likely to suffer from ED compared to those who have good glycemic control. This finding is consistent with those of many other authors $[3,17,18,26]$. It is noteworthy that a couple of studies had reported no significant relationship between glucose control and ED in diabetics $[27,28]$. Sustained hyperglycemia is a well recognized risk factor for nearly all diabetic complications. Although the effect of improving glycemic control was not investigated by this study, our findings strongly suggest a possible beneficial role of optimizing glycemic control in the prevention of ED in persons with type 2 diabetes and this area requires further evaluation.

We observed that subjects with ED had a significantly lower testosterone concentration than those with normal erectile function $(P<0.001)$. Furthermore, subjects with low testosterone, $<8 \mathrm{nmol} / \mathrm{L}$, were at least six times more likely to have ED. Kapoor et al. [29] had similarly reported significantly lower levels of both bioavailable testosterone and free testosterone in diabetic men with ED than in those without. Evidences such as these support the notion that androgens have a beneficial role in erectile function. Nonetheless, the role of androgens in the erectile process is not entirely clear and it has been reported that androgens play no direct role in penile erection [30]. However, there are many more animal and human studies which showed that androgens play important roles in penile erection [31-33]. Testosterone has been shown to regulate arterial flow and vasodilatation and nitric oxide synthesis and stimulates libido and the transmission of signaling in the spinal cord [31]. About a decade ago, a meta-analysis demonstrated that about a third of men with ED have androgen deficiency and concluded that androgen deficiency adversely affects penile erection [32]. Moreover, testosterone therapy in hypogonadal men has been shown to improve both libido and sexual performance [33].
The European Association of Urologists (EAU) and British Society for Sexual Medicine (BSSM) recommend that all patients with ED must undergo testosterone measurement before initiating treatment for ED [34].

Neither total cholesterol concentration nor any of the lipoprotein fractions (HDL, LDL, and TG) was significantly associated with ED in this study. This finding is consistent with two large population-based observational studies which reported no significant association between the circulating lipid levels and the risk of ED and concluded that although dyslipidemia is common in diabetics, it has no significant role in the pathogenesis of diabetic $\operatorname{ED}[3,35]$. An Italian study however reported a significant association between the so-called diabetic or atherogenic dyslipidemia (low HDL and high TG) and the risk of diabetic ED and concluded that this may be a result of the fact that both features of atherogenic dyslipidemia are components of the metabolic syndrome which has been shown to be a risk factor for ED [17]. Although we did not specifically evaluate for atherogenic dyslipidemia, we observed that the prevalence of dyslipidemia in this study was generally low and this may not be unrelated to the routine use of lipid lowering drugs (statins) in our centre. Furthermore, we found no association between ED and non-HDL cholesterol (TC-HDL cholesterol) which is generally considered to be a better predictor of cardiovascular risk than the concentrations of individual lipoprotein particles. Measurement of apolipoprotein-B (apo-B) would have helped to further elucidate the relationship between lipids and ED in this study. Unfortunately, such facility is lacking in our centre. This area therefore needs to be explored by other researchers in this subject.

\section{Conclusion}

In this small population of men with type 2 diabetes, a high frequency of erectile dysfunction was observed and this was of moderate-to-severe intensity in over half of those affected. The study also demonstrated that the risk factors for ED in the diabetic population were largely modifiable including poor glycemic control, testosterone deficiency, peripheral arterial disease, and autonomic neuropathy, while a longer duration of DM was noted as an important nonmodifiable risk factor. Based on these findings, we recommend that periodic assessment of erectile function should form part of routine diabetes care, focusing attention on the modifiable risk factors as this may go a long way in preventing ED, delaying its progression, or reversing established ED in persons with type 2 diabetes.

The limitations of this study include its cross-sectional nature which does not permit inference on cause and effect, lack of control group, and inability to measure free testosterone owing to financial constraint. Our inability to evaluate the effect of antihypertensive therapy on erectile function also constitutes a limitation requiring further evaluation. Finally, this study was conducted in a small population of men with type $2 \mathrm{DM}$ being managed at a tertiary healthcare centre. Thus the study population may represent those with more severe or advanced disease rather than the general population of men 
with type 2 diabetes mellitus. Therefore the findings from this study should be interpreted with caution.

$\begin{array}{ll}\text { Abbreviations } \\ \text { ED: } \quad \text { Erectile dysfunction } \\ \text { DM: } \quad \text { Diabetes Mellitus } \\ \text { WC: } \quad \text { Waist circumference } \\ \text { PAD: } \quad \text { Peripheral arterial disease } \\ \text { ABI: } \quad \text { Ankle brachial index } \\ \text { BP: } \quad \text { Blood pressure } \\ \text { HR: } \quad \text { Heart rate } \\ \text { IIEF: } & \text { International Index of Erectile Function } \\ \text { HbAlc: } & \text { Glycated hemoglobin } \\ \text { OHA: } & \text { Oral hypoglycemic agents } \\ \text { SD: } & \text { Standard deviation } \\ \text { OR: } & \text { Odds ratio. }\end{array}$

\section{Conflict of Interests}

The authors declare that there is no conflict of interests.

\section{Authors' Contribution}

All authors have made useful contributions to qualify for authorship as follows: Theophilus Ugwu conceptualized the study and contributed to literature search, data acquisition, and paper writing. Ignatius Ezeani and Samuel Onung contributed to the data analysis and interpretation and paper review. Babatope Kolawole and Rosemary Ikem contributed to study design and supervision, data interpretation, and critical revision of the paper for important intellectual content. All authors read and approved the final version of the paper.

\section{References}

[1] NIH Consensus Conference, "NIH consensus development panel on impotence," Journal of the American Medical Association, vol. 270, no. 1, pp. 83-90, 1993.

[2] D. K. McCulloch, I. W. Campbell, F. C. Wu, R. J. Prescott, and B. F. Clarke, "The prevalence of diabetic impotence," Diabetologia, vol. 18, no. 4, pp. 279-283, 1980.

[3] C.-C. Lu, B.-P. Jiann, C.-C. Sun, H.-C. Lam, C.-H. Chu, and J.-K. Lee, "Association of glycemic control with risk of erectile dysfunction in men with type 2 diabetes," Journal of Sexual Medicine, vol. 6, no. 6, pp. 1719-1728, 2009.

[4] H. A. Feldman, I. Goldstein, D. G. Hatzichristou, R. J. Krane, and J. B. McKinlay, "Impotence and its medical and psychosocial correlates: results of the Massachusetts Male Aging Study," Journal of Urology, vol. 151, no. 1, pp. 54-61, 1994.

[5] P. Dandona, S. Dhindsa, and A. Chandel, "Low testosterone in men with type 2 diabetes, a growing public health concern," Diabetes Voice, vol. 54, pp. 27-29, 2009.

[6] G. de Berardis, M. Franciosi, M. Belfiglio et al., "Erectile dysfunction and quality of life in type 2 diabetic patients: a serious problem too often overlooked," Diabetes Care, vol. 25, no. 2, pp. 284-291, 2002.

[7] A. Nicolosi, E. D. Moreira Jr., M. Villa, and D. B. Glasser, "A population study of the association between sexual function, sexual satisfaction and depressive symptoms in men," Journal of Affective Disorders, vol. 82, no. 2, pp. 235-243, 2004.

[8] P. Montorsi, P. M. Ravagnani, S. Galli et al., "Common grounds for erectile dysfunction and coronary artery disease," Current Opinion in Urology, vol. 14, no. 6, pp. 361-365, 2004.

[9] M. H. Cummings, D. Meeking, F. Warburton, and W. D. Alexander, "The diabetic male's perception of erectile dysfunction," Practical Diabetes International, vol. 14, no. 4, pp. 100-102, 1997.

[10] K. G. M. M. Alberti, P. Zimmet, and J. Shaw, "Metabolic syndrome-a new world-wide definition: a consensus statement from the International Diabetes Federation," Diabetic Medicine, vol. 23, no. 5, pp. 469-480, 2006.

[11] S. M. Grenon, J. Gagnon, and Y. Hsiang, "Ankle-brachial index for assessment of peripheral arterial disease," The New England Journal of Medicine, vol. 361, article e40, 3 pages, 2009.

[12] D. J. Ewing and B. F. Clarke, "Autonomic neuropathy: its diagnosis and prognosis," Clinics in Endocrinology and Metabolism, vol. 15, no. 4, pp. 855-888, 1986.

[13] R. C. Rosen, J. C. Cappelleri, M. D. Smith, J. Lipsky, and B. M. Pena, "Development and evaluation of an abridged 5-item version of the International Index of Erectile Function (IIEF5) as a diagnostic tool for erectile dysfunction," International Journal of Impotence Research, vol. 11, no. 6, pp. 319-326, 1999.

[14] J. K. Olarinoye, S. A. Kuranga, I. A. Katibi, O. S. Adediran, A. A. Jimoh, and E. O. Sanya, "Prevalence and determinants of erectile dysfunction among people with type 2 diabetes in Ilorin, Nigeria," The Nigerian Postgraduate Medical Journal, vol. 13, no. 4, pp. 291-296, 2006.

[15] A. Ogbera and A. Adedokun, "The prevalence of erectile dysfunction in Nigerians with diabetes mellitus," in Proceedings of the 17th World Congress of Sexology, Montreal, Canada, July 2005.

[16] E. Nieschlag, R. Swerdloff, H. M. Behre et al., "Investigation, treatment and monitoring of late-onset hypogonadism in males: ISA, ISSAM, and EAU recommendations," European Urology, vol. 48, no. 1, pp. 1-4, 2005.

[17] F. Giugliano, M. Maiorino, G. Bellastella, M. Gicchino, D. Giugliano, and K. Esposito, "Determinants of erectile dysfunction in type 2 diabetes," International Journal of Impotence Research, vol. 22, no. 3, pp. 204-209, 2010.

[18] D. Fedele, A. Bortolotti, C. Coscelli et al., "Erectile dysfunction in type 1 and type 2 diabetics in Italy," International Journal of Epidemiology, vol. 29, no. 3, pp. 524-531, 2000.

[19] T. Mulligan, M. F. Frick, Q. C. Zuraw, A. Stemhagen, and C. McWhirter, "Prevalence of hypogonadism in males aged at least 45 years: the HIM study," International Journal of Clinical Practice, vol. 60, no. 7, pp. 762-769, 2006.

[20] I. M. El-Kebbi, D. C. Ziemer, C. B. Cook, C. D. Miller, D. L. Gallina, and L. S. Phillips, "Comorbidity and glycemic control in patients with type 2 diabetes," Archives of Internal Medicine, vol. 161, no. 10, pp. 1295-1300, 2001.

[21] J. Belch, G. Stansby, C. Shearman et al., "Peripheral arterial disease-a cardiovascular time bomb," British Journal of Diabetes and Vascular Disease, vol. 7, no. 5, pp. 236-239, 2007.

[22] S. P. Marso and W. R. Hiatt, "Peripheral arterial disease in patients with diabetes," Journal of the American College of Cardiology, vol. 47, no. 5, pp. 921-929, 2006.

[23] C. Gazzaruso, S. Giordanetti, E. De Amici et al., "Relationship between erectile dysfunction and silent myocardial ischemia in apparently uncomplicated type 2 diabetic patients," Circulation, vol. 110, no. 1, pp. 22-26, 2004. 
[24] M. Ellenberg, "Impotence in diabetes: the neurologic factor," Annals of Internal Medicine, vol. 75, no. 2, pp. 213-219, 1971.

[25] A. Veves, C. M. Akbari, J. Primavera et al., "Endothelial dysfunction and the expression of endothelial nitric oxide synthetase in diabetic neuropathy, vascular disease, and foot ulceration," Diabetes, vol. 47, no. 3, pp. 457-463, 1998.

[26] B. C. Unadike, A. Eregie, and A. E. Ohwovoriole, "Association between glycemic control and erectile dysfunction among Nigerian diabetic patients," Diabetes International, vol. 5, pp. 15$16,2008$.

[27] H. Zheng, W. Fan, G. Li, and T. Tam, "Predictors for erectile dysfunction among diabetics," Diabetes Research and Clinical Practice, vol. 71, no. 3, pp. 313-319, 2006.

[28] A. Al-Hunaya, M. Al-Mutar, E. O. Kehinde, L. Thalib, and M. Al-Ghorory, "The prevalence and predictors of erectile dysfunction in men with newly diagnosed with type 2 diabetes mellitus," BJU International, vol. 99, no. 1, pp. 130-134, 2007.

[29] D. Kapoor, H. Aldred, S. Clark, K. S. Channer, and T. H. Jones, "Clinical and biochemical assessment of hypogonadism in men with type 2 diabetes: correlations with bioavailable testosterone and visceral adiposity," Diabetes Care, vol. 30, no. 4, pp. 911-917, 2007.

[30] S. G. Korenman, J. E. Morley, A. D. Mooradian et al., "Secondary hypogonadism in older men: its relation to impotence," Journal of Clinical Endocrinology and Metabolism, vol. 71, no. 4, pp. 763769, 1990.

[31] A. M. Traish, I. Goldstein, and N. N. Kim, "Testosterone and erectile function: from basic research to a new clinical paradigm for managing men with androgen insufficiency and erectile dysfunction," European Urology, vol. 52, no. 1, pp. 54-70, 2007.

[32] A. M. Isidori, E. Giannetta, D. Gianfrilli et al., "Effects of testosterone on sexual function in men: results of a metaanalysis," Clinical Endocrinology, vol. 63, no. 4, pp. 239-243, 2005.

[33] J. D. Dean and C. Carnegie, "Long term effects of Testim-1\% testosterone gel in hypogonadal men," Reviews in Urology, vol. 6, pp. 522-529, 2004.

[34] G. Hackett, P. Kell, D. Ralph et al., "British society for sexual medicine guidelines on the management of erectile dysfunction," Journal of Sexual Medicine, vol. 5, no. 8, pp. 1841-1865, 2008.

[35] R. R. Wing, R. C. Rosen, J. L. Fava et al., "Effects of weight loss intervention on erectile function in older men with type 2 diabetes in the Look AHEAD trial," Journal of Sexual Medicine, vol. 7, no. 1, part 1, pp. 156-165, 2010. 


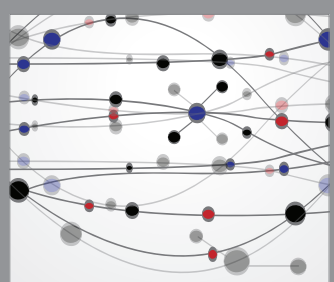

The Scientific World Journal
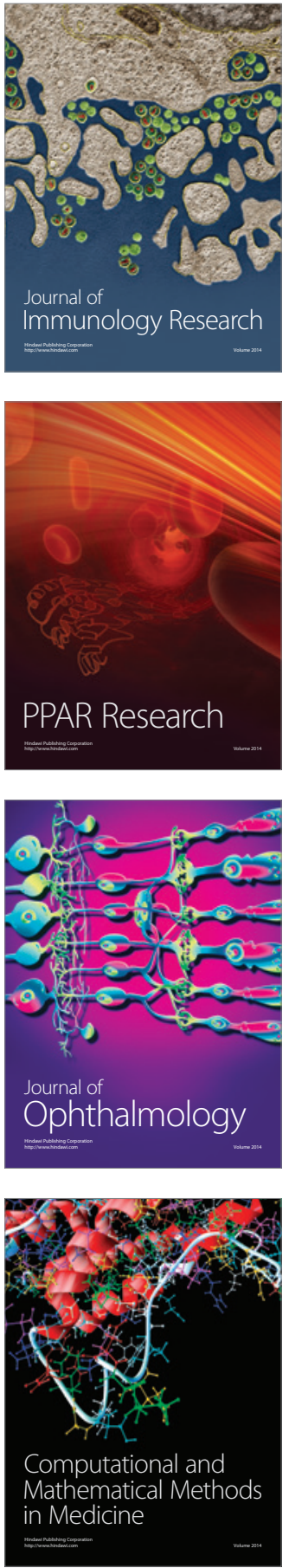

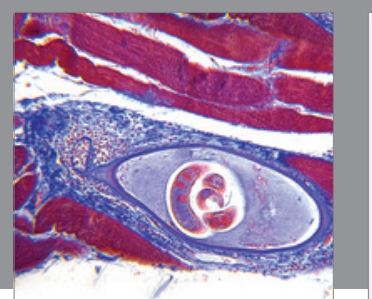

Gastroenterology Research and Practice

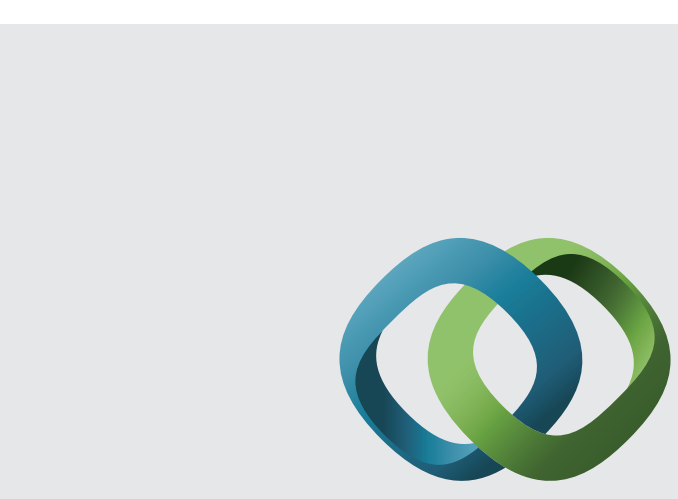

\section{Hindawi}

Submit your manuscripts at

http://www.hindawi.com
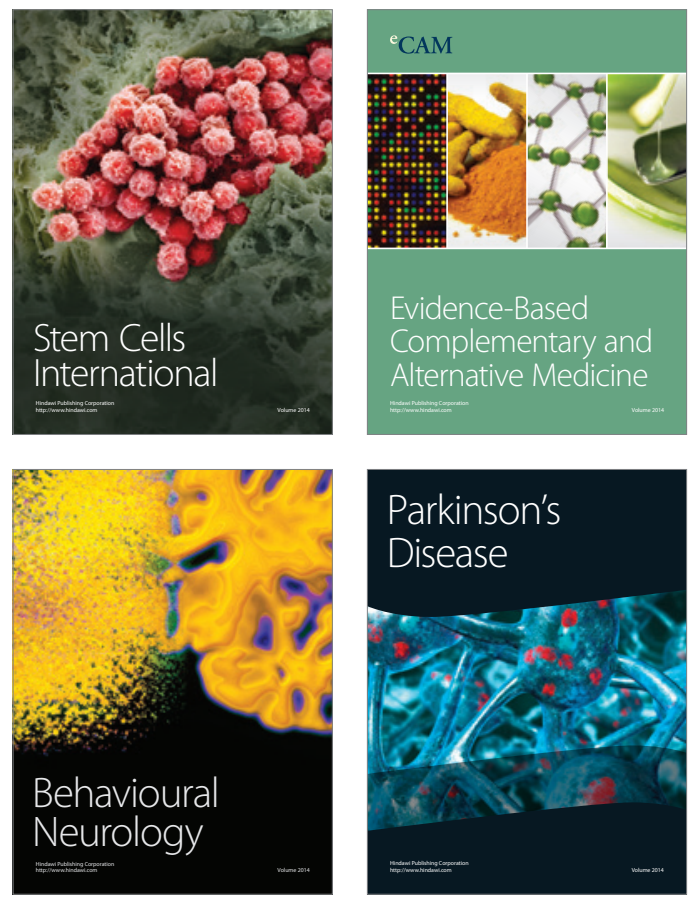
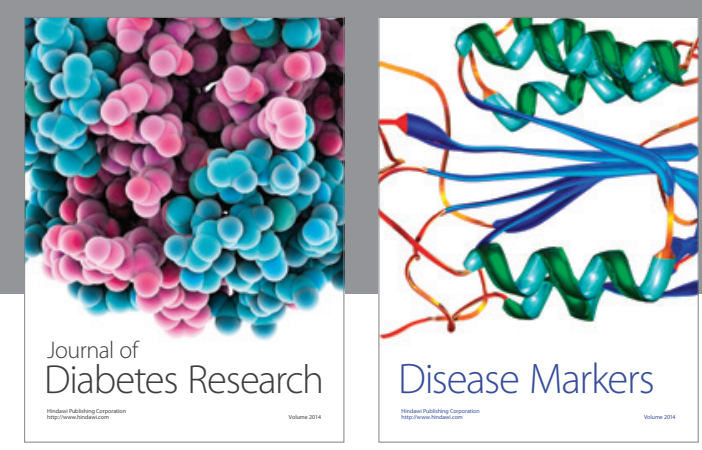

Disease Markers
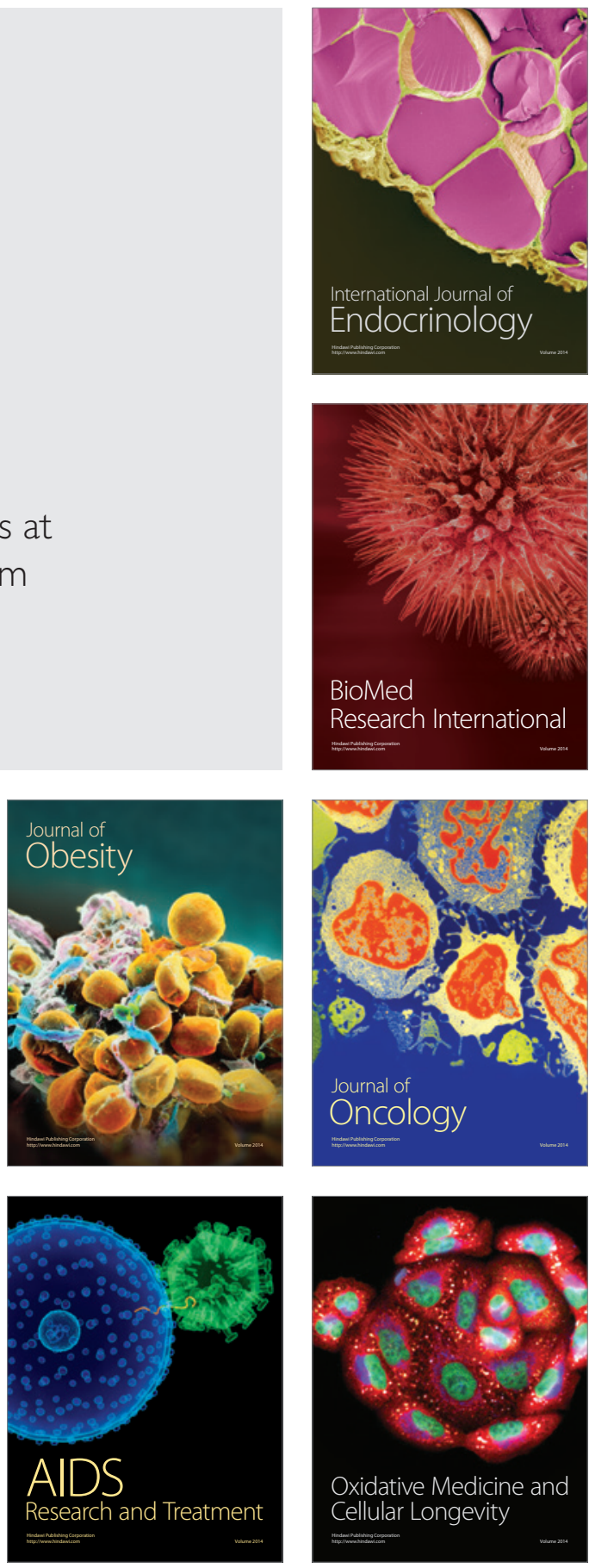